\title{
Pengaruh Implementasi Forced Distribution Rating Performance Appraisal terhadap Task Performance: Motivasi dan Retensi sebagai Mediasi
}

\section{The Effect of Forced Distribution Rating Performance Appraisal Implementation on Task Performance: Motivation and Retention as Mediation}

\author{
Dimas Andi Satriyoadi Hidayat ${ }^{1)}$, Juwita Sari ${ }^{2)}$, Ahmad Rizki Sridadi ${ }^{3)}$ \\ ${ }^{1)}$ Magister Manajemen, Fakultas Ekonomi dan Bisnis, Universitas Airlangga, Kota Surabaya \\ ${ }^{2}$ Departemen Manajemen, Sekolah Tinggi Ilmu Ekonomi Indonesia Surabaya (STIESIA) \\ ${ }^{3)}$ Fakultas Ekonomi dan Bisnis, Universitas Airlangga, Kota Surabaya \\ e-mail korespondensi: dimas.andi.sh@gmail.com
}

\begin{tabular}{|l|}
\hline Info Artikel \\
\hline Riwayat Artikel : \\
Diterima: 07 Juli 2021 \\
Disetujui: 15 September 2021 \\
Dipublikasikan: Januari 2022 \\
\hline Nomor DOI \\
10.33059/jseb.v13i1.3910 \\
Cara Mensitasi : \\
Hidayat, D. A. S., Sari, J., \& \\
Sridadi, A. R. (2022). Pengaruh \\
implementasi forced \\
distribution rating performance \\
appraisal (FDRPA) terhadap \\
task performance: Motivasi dan \\
retensi sebagai mediasi. Jurnal \\
Samudra Ekonomi dan Bisnis, \\
13(1), 100-112. doi: 10.33059/ \\
jseb.v13i1.3910.
\end{tabular}

Abstrak
Salah satu metode penilaian kinerja sumber daya manusia yang cukup sering
digunakan, namun belum cukup banyak dibahas dalam studi empiris adalah
Forced Distribution Rating Performance Appraisal (FDRPA). Penelitian ini
menguji pengaruh FDRPA terhadap task performance yang dimediasi motivasi
dan retensi. Uji hipotesis menggunakan data yang berasal dari survei kepada
relationship manager di salah satu bank di Surabaya yang menerapkan system
FDRPA. Responden yang terkumpul berjumlah 81 orang. Hasil menunjukkan
bahwa FDRPA berpengaruh positif terhadap task performance. Motivasi dan
retensi juga menunjukkan peran mediasi hubungan antara FDRPA terhadap task
performance. Hal ini menunjukkan manajemen perlu memahami bahwa dalam
peningkatan task performance ada faktor-faktor berupa motivasi dan retensi yang
perlu diperhatikan juga. Selain itu, manajemen diharapkan mampu mengelola
penerapan FDRPA dengan baik, agar manfaat positif tersebut dapat terus
berkelanjutan.

Kata Kunci: Forced Distribution Rating Performance Appraisal, Motivasi, Retensi, Task Performance.

\begin{tabular}{|l|}
\hline Article Info \\
\hline Article History: \\
Received: 07 July 2021 \\
Accepted: 15 September 2021 \\
Published: January 2022 \\
\hline DOI Number: \\
10.33059/jseb.v13i1.3910 \\
How to cite: \\
Hidayat, D. A. S., Sari, J., \& \\
Sridadi, A. R. (2022). Pengaruh \\
implementasi forced \\
distribution rating performance \\
appraisal (FDRPA) terhadap \\
task performance: Motivasi dan \\
retensi sebagai mediasi. Jurnal \\
Samudra Ekonomi dan Bisnis, \\
13(1), 100-112. doi: 10.33059/ \\
jseb.v13i1.3910.
\end{tabular}

\section{Abstract}

The assessment method of human resource that is often used, but has not been widely discussed in empirical studies is the Forced Distribution Rating Performance Appraisal (FDRPA). This study examines the effect of FDRPA on task performance mediated by motivation and retention. Data from Relationship Managers at a bank in Surabaya that implements the FDRPA system. Data collect is 81 people. The results show that FDRPA has a positive effect on task performance. Where, motivation and retention also show the mediating role of the relationship between FDRPA on task performance. This shows that management needs to understand that the factors in improving the performance of the task, there are variable motivation and retention that need to be considered as well. Furthermore, management is expected to be able to manage the implementation of FDRPA well, so that these positive benefits can continue to be sustainable.

Keywords: Forced Distribution Rating Performance Appraisal, Motivation, Retention, Task Performance. 


\section{PENDAHULUAN}

Force distribution rating performance appraisal (FDRPA) merupakan penerapan metode penilaian kinerja oleh perusahaan dengan relative basis, yaitu pencapaian pegawai diukur berdasarkan perbandingan nilai pegawai yang bersangkutan dengan pegawai lainnya (Burnham, 2015; Grote, 2006; Chattopadhyay, 2019). FDRPA telah banyak diadopsi perusahaan-perusahaan di Amerika Serikat diantaranya General Electric, Cisco System, Hewlett-Packard, Microsoft, Lucent, Intel, Goodyear Tire, Ford, Goldman Sachs, American Express, Sun Microsystems dan Conoco (Bates, 2003; Loberg et al., 2021). Bahkan, ada estimasi bahwa 20\% dari keseluruhan bisnis di Amerika Serikat dan hingga 25\% dari Fortune 500 menggunakan beberapa tipe sistem evaluasi kinerja berupa FDRPA (Osborne \& McCann, 2004).

Ada empat elemen kunci dari FDRPA yaitu konsekuensi yang diberikan untuk low performers, perbedaaan reward untuk top performers, frekuensi dari feedback yang diberikan, dan ukuran kelompok pembanding (Blume et al., 2009, 2013). FDRPA memiliki dampak yang disebut sebagai "incentive effect", dimana manajer memberikan reward kepada top performers berupa kenaikan gaji atau promosi, memberikan insentif yang lebih kecil untuk average performers dan memberhentikan yang berada pada kelompok bottom performers (Gerhart \& Fang, 2015; Rynes et al., 2005). Expectancy theory menjelaskan bahwa mengaitkan insentif pada kinerja akan meningkatkan motivasi untuk mendorong usaha dan juga kinerja (Lawler, 1973; Moon et al., 2015). Hal ini karena motivasi adalah fungsi dari persepsi individu atas lingkungannya dan ekspektasi yang mereka bentuk berdasarkan persepsi tersebut.

Selain itu, FDRPA memiliki "sorting effect" melalui daya tarik yang berbeda dan proses retensi (Rynes et al., 2005). Setiap organisasi yang menerapkan FDRPA dirasa memiliki daya tarik tersendiri bagi calon pegawai berpotensi tinggi, sekaligus juga mampu mempertahankan pegawai berkinerja tinggi yang saat ini berada dalam perusahaan. Hal ini didukung oleh beberapa penelitian yang mengemukakan bahwa pegawai dengan kemampuan kognitif (Blume et al., 2013), keyakinan diri (Blume et al., 2013; Cable \& Judge, 1994) dan kebutuhan akan pencapaian yang tinggi (Turban \& Keon, 1993; Yu, 2014) akan cenderung tertarik pada organisasi yang memberikan reward pada pegawai berdasarkan kinerjanya. Kondisi ini selanjutnya dapat mendorong pegawai yang telah ada untuk meningkatkan kinerjanya secara berkelanjutan agar dapat tetap bersaing dengan pegawai baru (Moon et al., 2015).

Kinerja merupakan perilaku individu yang diharapkan oleh organisasi, bukan hasil dari pekerjaan yang dilakukan oleh individu tersebut (Aguinis, 2007, 2013). Beberapa pengukuran kinerja menggunakan hasil dari pekerjaan sebagai parameternya dikarenakan perilaku dari individu memiliki sifat tidak dapat diukur atau diamati secara langsung (Aguinis, 2013; Hausknecht et al., 2008; Moon et al., 2015). Task performance merupakan dimensi dari kinerja dan dapat didefinisikan sebagai serangkaian aktifitas yang mentransformasi bahan baku menjadi barang dan jasa yang diproduksi oleh suatu organisasi, atau aktivitas yang membantu proses transformasi itu dengan penyediaan pasokan bahan baku, distribusi barang jadi, menyediakan perencanaan bersifat penting, koordinasi, pengawasan, ataupun fungsifungsi staf yang membantu organisasi menjalankan aktivitasnya secara efektif dan efisien (Aguinis, 2007, 2013).

Blume et al. (2013) menemukan bahwa responden yang memiliki nilai kemampuan kognitif yang lebih tinggi cenderung lebih terarik pada organisasi yang menerapkan 
FDRPA daripada responden yang memiliki nilai kemampuan kognitif yang rendah. Sementara itu, Aguinis (2013) mengutarakan bahwa task performance dipengaruhi oleh keahlian dan kemampuan individu seperti kemampuan kognitif. Secara empiris, Berger et al. (2013) dan Giumetti et al. (2015) menemukan bahwa produktivitas dengan menggunakan FDRPA secara signifikan lebih tinggi sekitar 8 persen jika dibandingkan dengan absolute rating system. Hal ini karena FDRPA dapat memberi dampak terhadap task performance yang lebih tinggi jika dalam waktu yang relatif lebih singkat, karena secara tidak langsung bisa memotivasi usaha karyawan sebagaimana mampu menarik minat dan mempertahankan karyawan pada kategori peringkat teratas (Moon et al., 2015).

Minimnya jumlah studi empiris yang membahas hubungan keduanya menjadikan pentingnya meneliti bagaimanaa pengaruh FDRPA terhadap task performance. Tujuan penelitian ini adalah menganalisis mengenai bagaimana pengaruh dari penerapan FDRPA pada perusahaan dan bagaimana pengaruhnya terhadap task performance setiap karyawan di dalamnya. Lebih jauh, penelitian ini mengkaitkan hubungan itu dengan motivasi dan retensi sebagai variabel yang memediasi hubungan keduanya. Penelitian ini diharapkan dapat memberikan gambaran kepada manajer perusahaan hal-hal penting apa saja yang perlu diperhatikan dalam penerapan FDRPA, sehingga setiap perusahaan memiliki strategi dalam penerapannya untuk memberi manfaat secara berkelanjutan bagi perusahaan.

\section{Task Performance}

Task performance adalah efektivitas pekerjaan saat ini yang berkontribusi terhadap inti teknis organisasi baik secara langsung atau secara tidak langsung (Motowidlo \& Van Scotter, 1994; Pradhan \& Jena, 2017). Task performance juga dapat diartikan sebagai serangkaian aktifitas yang mentransformasi bahan mentah menjadi barang dan jasa yang diproduksi oleh suatu organisasi, atau sebagai aktivitas yang membantu proses transformasi tersebut dengan penyediaan bahan dasar/ pasokan/bahan baku, pendistribusian barang jadi, menyediakan perencanaan, kordinasi, pengawasan atau fungsi-fungsi staf yang membantu organisasi menjalankan fungsi secara efektif dan efisien (Aguinis, 2007, 2013).

Task performance pada penelitian ini diukur menggunakan empat kriteria yang dikembangkan Pearce \& Porter (1986), yaitu: (1) kinerja secara keseluruhan; (2) ketepatan waktu penyelesaian tugas; (3) kualitas kinerja; dan, (4) pencapaian tujuan kerja.

\section{Forced Distribution Rating Performance Appraisal (FDRPA)}

FDRPA dapat didefinisikan sebagai sebuah sistem penilaian kinerja yang mendesak supervisor untuk mendistribusikan pegawai ke dalam beberapa kategori dari persentase yang sudah ditentukan sebelumnya berdasarkan kinerja pegawai relatif terhadap kinerja pegawai lainnya (Berger et al., 2013; Blume et al., 2009; Hartmann \& Schreck, 2018; Moon et al., 2015). Dalam kata lain, FDRPA dapat didefinisikan sebagai sistem evaluasi berbasis kinerja dimana karyawan diberi peringkat satu sama lain berdasarkan skema atau desain tertentu (Osborne \& McCann, 2004; Thomason et al., 2018).

Sistem ini memaksa supervisor untuk membandingkan karyawan satu dengan yang lain (Stewart et al., 2010) dan membaginya menjadi tiga kategori: top performers, vitals dan poor performers (Mulligan \& Schaefer, 2011). Konsekuensi dari klasifikasi ini sangat penting bagi karyawan, karena karyawan yang berkinerja terbaik mendapatkan bonus tinggi, sementara karyawan yang berkinerja buruk tidak menerima bonus atau bahkan 
dapat kehilangan pekerjaan jika peringkat mereka tetap rendah (Loberg et al., 2021; Moon et al., 2015).

Jayasuriya \& Dasanayaka (2016) dalam penelitiannya menggunakan dua bagian utama untuk mengukur FDRPA. Bagian pertama adalah pendahuluan yang digunakan untuk mengukur pemahaman responden berkaitan dengan FDRPA, dan bagian kedua adalah evaluasi dari penerapan FDRPA dalam perusahaan. Dengan cara ini, FDRPA dapat terlihat dari bagaimana pihak relationship manager memahami dan menilai penerapan FDRPA itu sendiri.

Berger et al. (2013) serta Hartmann \& Schreck (2018) melakukan studi yang membandingkan efek kinerja FDRPA atas kondisi peringkat absolut. Hasil yang ditemukan oleh keduanya adalah adanya peningkatan produktivitas karyawan saat menggunakan kondisi FDRPA. Selain itu, melalui studi banding yang dilakukan oleh Malhotra \& Mukherjee (2013) diperoleh bahwa rata-rata responden merasa bahwa dampak penerapan FDRPA terhadap kinerja berada di atas rata-rata. Berdasarkan sejumlah telaah empiris itu, maka dalam penelitian ini dihipotesiskan terdapat hubungan yang positif dan signifikan antara implementasi FDRPA terhadap task performance.

\section{Motivasi}

Motivasi dideskripsikan sebagai sebuah dorongan yang tidak terlihat, mengarahkan, memberikan energi, serta mempertahankan perilaku dari waktu ke waktu dan melalui berbagai keadaan (Bawa, 2019; Fudge \& Schlacter, 1999; M. Badubi, 2017; Reizer et al., 2019). Penelitian ini menggunakan pendekatan expectancy theory yang diperkenalkan oleh Vroom (1964) dimana motivasi adalah fungsi dari persepsi individu atas lingkungannya dan ekspektasi yang mereka bentuk berdasarkan persepsi tersebut.
Fudge \& Schlacter (1999) dan Wigfield \& Eccles (2000) menjelaskan beberapa faktor yang terdapat dalam expectancy theory. Faktor pertama adalah effort-performance expectancy, yaitu memperhatikan persepsi individu dimana effort secara positif berhubungan dengan tingkat kinerja dihasilkan. Faktor kedua adalah performance-outcome expectancy, atau instrumentality, memperhatikan ekspektasi seseorang bahwa reward yang akan dia terima sangat berkaitan dengan tingkat kinerja yang dihasilkan. Faktor ketiga adalah valence, yang menjelaskan mengenai seberapa besar seseorang menilai sebuah reward. Semakin besar seseorang menilai reward yang akan dihasilkan berdasarkan usahanya, maka dia akan semakin termotivasi untuk mendapatkan reward tersebut (Kanwal \& Syed, 2017; Seng \& Arumugam, 2017).

Dalam konsep FDRPA dikenal istilah "incentive effect", dimana manajer akan memberikan penghargaan berupa insentif atau promosi yang tinggi kepada karyawan yang berkinerja tinggi, insentif yang lebih rendah kepada karyawan dengan kinerja rata-rata, dan kemungkinan pemutusan hubungan kerja bagi karyawan yang memiliki kinerja rendah (Chattopadhayay \& Ghosh, 2012; Moon et al., 2015; Rynes et al., 2005). Selain itu, penelitian yang dilakukan Grote (2006) serta Seng \& Arumugam (2017) menunjukkan bahwa seorang karyawan yang melihat rekan kerjanya mendapat sanksi karena hasil kinerja yang rendah akan meningkatkan hasil kinerja mereka.

Sehubungan dengan hal tersebut dan mengacu pada teori ekspektansi oleh Vroom 1964 (Parijat \& Bagga, 2014), dimana terdapat tiga faktor yang saling berperan dan saling berinteraksi dalam motivasi. Semakin besar seseorang mengevaluasi imbalan yang akan dihasilkan berdasarkan usahanya, maka semakin termotivasi dia untuk mendapatkan imbalan tersebut (Fudge \& Schlacter, 1999; 
Kanwal \& Syed, 2017; Wigfield \& Eccles, 2000). Pearce \& Porter (1986) juga menyatakan bahwa karyawan akan menunjukkan usaha yang lebih besar ketika mereka percaya bahwa mereka akan menerima penghargaan atas pencapaian kinerja mereka.

Berdasarkan hasil telaah konseptual yang dilakukan, maka dihipotesiskan motivasi mampu memediasi pengaruh implementasi FDRPA terhadap task performance.

\section{Retensi}

Retensi merupakan sebuah elemen kritis pada sebuah pendekatan organisasi yang lebih umum mengenai talent management (Ghosh et al., 2013; Hausknecht et al., 2008). Beberapa peneliti mendefinisikan retensi karyawan sebagai bagian dari implementasi strategi yang terintegrasi atau sistem yang didesain untuk meningkatkan produktivitas dengan mengembangkan proses kerja yang menarik, pengembangan, retensi, dan penggunaan sumber daya manusia dengan keahlian dan bakat yang dibutuhkan untuk mencapai kebutuhan bisnis saat ini maupun di masa yang akan datang (Al Kurdi et al., 2020; Naim \& Lenka, 2018; Syahreza et al., 2017; Wassem et al., 2019).

Penerapan FDRPA dapat memiliki "sorting effect" melalui proses daya tarik dan retensi (Rynes et al., 2005), dimana melalui penerapan FDRPA maka perusahaan akan berpotensi untuk menarik karyawan yang berkinerja tinggi. Hal ini diperkuat oleh beberapa penelitian sebelumnya yang menunjukkan bahwa karyawan yang memiliki kemampuan kognitif relatif tinggi kepercayaan diri yang tinggi dan kebutuhan untuk berprestasi akan cenderung tertarik pada perusahaan yang memberikan penghargaan kepada karyawan berdasarkan kinerja mereka (Blume et al., 2013; Loberg et al., 2021; Cable \& Judge, 1994; Yu, 2014; Turban \& Keon, 1993). Dengan demikian, bisa dikata- kan bahwa seorang calon karyawan akan memandang perusahaan yang menerapkan sistem FDRPA sebagai tempat yang ideal baginya, dikarenakan reward, bakat dan kemampuannya bias dikenali dan dikembangkan (Seng \& Arumugam, 2017). Karyawan yang berkinerja tinggi karenanya berusaha untuk terus mengembangkan potensinya agar tetap kompetitif.

Di sisi lain, mengacu kepada teori expectancy, perusahaan yang tidak memberi penghargaan kepada karyawan berdasarkan kinerjanya akan membuat karyawan yang berkinerja tinggi membandingkan upaya dan hasil yang mereka dapatkan relatif terhadap karyawan yang berkinerja rendah. Beberapa faktor retensi karyawan berkinerja tinggi termasuk kompensasi dan penghargaan untuk pekerjaan, ketersediaan pekerjaan yang menantang, peluang untuk dipromosikan dan belajar, suasana yang mendukung di dalam organisasi, hubungan yang positif dengan rekan kerja, pekerjaan, keseimbangan yang sehat antara kehidupan profesional dan pribadi, serta komunikasi yang baik. Faktorfaktor ini merupakan beberapa keuntungan yang dapat diperoleh oleh perusahaan yang menerapkan FDRPA (Cook, 2012; Grote, 2006; Stewart et al., 2010; M. Badubi, 2017).

Ghosh et al. (2013), Hausknecht et al. (2008) serta Syahreza et al. (2017) selain itu juga menjelaskan bahwa ada beberapa faktor yang turut berperan dalam retensi, yaitu kesempatan untuk berkembang, unsur keterikatan, penghargaan ekstrinsik, pengaturan kerja yang bersifat fleksibel, investasi waktu, kepuasan kerja, kurangnya alternatif, lokasi pekerjaan, pengaruh diluar pekerjaan, sikap komitmen organisasi, keadilan organisasi, dan nama baik organisasi. Sejumlah penelitian terdahulu menyatakan bahwa perusahaan yang menerapkan perlakuan berbeda terhadap karyawan berdasarkan kinerjanya terbukti dapat membantu perusahaan tersebut untuk 
mempertahankan karyawan yang berkinerja tinggi dan pada tingkat yang lebih tinggi; sementara pada saat yang sama memberhentikan karyawan yang berkinerja rendah (Loberg et al., 2021; Hamukwaya \& Yazdanifard, 2014; Kanwal \& Syed, 2017; Seng \& Arumugam, 2017; Zenger, 1992).

Retensi karyawan yang berkinerja tinggi menjadi perhatian serius bagi akademisi dan praktisi di bidang manajemen sumber daya manusia. Karyawan yang berkinerja tinggi berperan penting dalam proses pembelajaran dan pengembangan karyawan, dimana wawasan dan keahlian mereka menjadi kunci bagi perusahaan untuk tetap kompetitif (AlJedaia \& Mehrez, 2020; Jayasuriya \& Dasanayaka, 2016). Ditinjau dari kinerja organisasi, terdapat pengaruh yang signifikan antara turnover karyawan berkinerja tinggi atas kinerja perusahaan, sehingga FDRPA dapat meningkatkan kinerja tugas melalui sorting effect yang dimiliki dan potensi untuk imbalan dan ancaman hukuman dapat mendorong karyawan untuk memaksimalkan upaya kinerja mereka (Kwon et al., 2012; Moon et al., 2015; Rynes et al., 2005; Zheng et al., 2012).

Berdasarkan hasil telaah konseptual yang dilakukan tersebut, maka dihipotesiskan bahwa retensi mampu memediasi pengaruh implementasi FDRPA atas task performance.

\section{METODE PENELITIAN}

Penelitian kuantitatif ini menggunakan metode survei lapangan dengan penyebaran kuesioner secara online kepada responden. Data primer yang diperoleh selanjutnya diolah menggunakan metode Structural Equation Modeling (SEM) menggunakan software Smart PLS 3.

Penggunaan metode analisis SEM membutuhkan jumlah responden yang besar (Sari \& Suhariadi, 2019; Zheng et al., 2012). Ukuran sampel sebaiknya berjumlah lima sampai 10 kali jumlah structural path (Hair et al., 2014)). Dalam model penelitian ini terdapat 7 structural path, sehingga bila diambil jumlah syarat minimal yakni 10 kali jumlah path, maka jumlah yang dibutuhkan dalam penelitian ini adalah 70 sampel.

Atas dasar itu, relationship manager yang menjadi populasi adalah yang tercatat sebagai karyawan aktif pada data internal perusahaan pada saat dilakukan penelitian. Total populasi penelitian ini berjumlah 87 orang yang seluruhnya digunakan sebagai responden. Dari total kuesioner yang dibagikan tersebut, kuesioner yang kembali pada peneliti berjumlah 81 responden atau 93,10 persen. Jumlah ini dinilai sudah sangat memenuhi untuk dianalisis bagi penelitian ini.

Variabel-variabel yang dianalisis adalah task performance sebagai variabel dependen; FDRPA sebagai variabel independen, serta motivasi dan retensi merupakan variabel mediasi. Hasil penyebaran awal kuesioner memperoleh nilai AVE untuk masing-masing indikator dari variabel-variabel itu semuanya bernilai lebih besar dari 0,5; sehingga dinyatakan indikator-indikator itu telah memenuhi discriminant validity (Ghozali, 2009).

Berikutnya, nilai composite reliability dari masing-masing indikator pada variabelvariabel penelitian ini semuanya bernilai lebih dari 0.7; yang berarti indikator-indikator tersebut sudah konsisten dan telah memenuhi composite reliability. Dengan demikian, dapat dinyatakan indikator-indikator yang digunakan dalam penelitian ini telah memenuhi syarat outer loading dan termasuk reliabel (Ghozali, 2009; Hair et al., 2014).

Tahap berikutnya dari analisis data bertujuan untuk mengetahui ada tidaknya pengaruh antar variabel-variabel dalam model struktural penelitian ini. Pengujian dilakukan menggunakan uji $\mathrm{t}$ (t-test) yaitu dengan membandingkan nilai $t$-statistik dengan nilai $t$-tabel (yaitu, 1,96) pada taraf signifikansi $(\alpha)$ 
sebesar 0,05 (Hair et al., 2014; Sari \& Suhariadi, 2019).

\section{HASIL ANALISIS}

Proses pengujian atas pengaruh antara variabel-variabel yang dianalisis menunjukkan jalur pengaruh langsung (direct effect) serta jalur pengaruh tidak langsung (indirect effect). Hasil-hasil yang diperoleh terangkum dalam Tabel 1 dan Tabel 2.

Berdasarkan Tabel 1 dapat diidentifikasi bahwa FDRPA memiliki pengaruh langsung secara positif dan signifikan baik terhadap task performance, motivasi maupun retensi. Dengan demikian, hipotesis pertama $\left(\mathrm{H}_{1}\right)$ dalam penelitian bisa dibuktikan secara empiris. Artinya, apabila terjadi peningkatan intensitas atas implementasi FDRPA pada penilaian kinerja di dalam organisasi, maka berdampak meningkatkan task performance pegawai dengan asumsi bahwa variabelvariabel lainnya tidak mengalami perubahan.

Tabel 1 juga menunjukkan motivasi atau retensi memiliki pengaruh langsung bersifat positif dan signifikan terhadap task performance. Hasil ini menyatakan bahwa jika terjadi peningkatan salah satu di antara motivasi atau retensi pada diri pegawai maka akan mampu meningkatkan task performance organisasi, dengan asumsi bahwa variabelvariabel lainnya tidak mengalami perubahan.

Hasil pengujian atas pengaruh tidak langsung yang terangkum dalam Tabel 2 mengidentifikasi bahwa baik motivasi atau retensi merupakan mediator dengan pengaruh bersifat positif dan signifikan terhadap jalur hubungan antara FDRPA terhadap task performance. Artinya, baik motivasi ataupun retensi bersifat memperkuat pengaruh dari implementasi FDRPA atas task performance yang dicapai pegawai perusahaan.

Berikutnya, berdasarkan hasil-hasil yang terangkum dalam Tabel 3, terlihat nilai koefisien determinasi $\left(\mathrm{R}^{2}\right)$ dari motivasi sebesar 0,351, retensi sebesar 0,382, dan task performance sebesar 0,650. Artinya, ketiga variabel tersebut tergolong moderat karena nilai $\mathrm{R}^{2}$ berada dalam rentang 0,33 sampai 0,67 (Ghozali, 2009). Namun demikian, task performance terlihat memiliki nilai $\mathrm{R}^{2}$ yang paling besar dan mendekati kuat yaitu 0,650. Hal ini menunjukkan FDRPA sebagai variabel independen memiliki akurasi prediksi paling kuat atas task performance jika dibandingkan variabel-variabel independen lainnya (Hair et al., 2014).

Tabel 1. Hasil Pengujian Pengaruh Langsung

\begin{tabular}{lcccc}
\hline \multicolumn{1}{c}{ Direct Effect } & Coefficient of Effect & t-statistic & Keputusan & Pembuktian \\
\hline FDRPA $\rightarrow$ Motivasi & 0,592 & 7,822 & Signifikan & Terbukti \\
FDRPA $\rightarrow$ Retensi & 0,618 & 9,888 & Signifikan & Terbukti \\
FDRPA $\rightarrow$ Task Performance & 0,151 & 2,002 & Signifikan & Terbukti \\
Motivasi $\rightarrow$ Task Performance & 0,405 & 4,222 & Signifikan & Terbukti \\
Retensi $\rightarrow$ Task Performance & 0,358 & 4,086 & Signifikan & Terbukti \\
\hline
\end{tabular}

Sumber: Data primer (diolah), 2021.

Tabel 2. Hasil Pengujian Pengaruh Tidak Langsung

\begin{tabular}{lcccc}
\hline \multicolumn{1}{c}{ Indirect Effect } & Coefficient of Effect & t-statistic & Keputusan & Pembuktian \\
\hline $\begin{array}{l}\text { FDRPA } \rightarrow \text { Motivasi } \rightarrow \text { Task } \\
\text { Performance }\end{array}$ & 0,240 & 3,716 & Signifikan & Terbukti \\
$\begin{array}{l}\text { FDRPA } \rightarrow \text { Retensi } \rightarrow \text { Task } \\
\text { Performance }\end{array}$ & 0,221 & 3,776 & Signifikan & Terbukti \\
\hline
\end{tabular}

Sumber: Data primer (diolah), 2021. 
Tabel 3. Hasil Pengujian $R$-Square $\left(\mathbf{R}^{2}\right)$

\begin{tabular}{ccc}
\hline Variabel & Nilai $\boldsymbol{R}$-Square & Deskripsi \\
\hline Motivasi & 0,351 & Moderat \\
Retensi & 0,382 & Moderat \\
Task Performance & 0,650 & Moderat \\
\hline
\end{tabular}

Sumber: Data primer (diolah), 2021.

\section{Pembahasan}

Hubungan FDRPA dan Task Performance

Hasil analisis dalam penelitian ini menunjukan terdapatnya pengaruh positif antara FDRPA terhadap task performance. Hal ini sejalan dengan beberapa temuan empiris terdahulu bahwa dengan diterapkannya FDRPA maka potensi kinerja setiap individu dapat meningkat secara signifikan; dimana peningkatan tersebut diharapkan akan timbul saat awal-awal tahun penerapannya (Jayasuriya \& Dasanayaka, 2016; Blume et al., 2013; Moon et al., 2015; Scullen et al., 2005).

Hasil penelitian ini juga memperluas beberapa temuan empiris terdahulu bahwa produktivitas pegawai akan bisa mengalami peningkatan jika perusahaannya menggunakan FDRPA (Berger et al., 2013; Cook, 2012; Chattopadhyay, 2019; Stewart et al., 2010). Hasil studi komparatif yang dilakukan oleh Malhotra \& Mukherjee (2013) juga menunjukkan bahwa rata-rata responden merasa bahwa dampak FDRPA terhadap kinerja adalah di atas rata-rata.

\section{Hubungan FDRPA dan Motivasi}

Berdasarkan hasil penelitian ini ditemukan terdapat pengaruh positif antara FDRPA terhadap motivasi. Sebagaimana dijelaskan oleh Moon et al. (2015) serta Rynes et al. (2005) bahwa FDRPA memiliki kemampuan untuk memotivasi pegawai di dalam suatu organisasi melalui "incentive effect". Dalam hal ini, manajer akan memberi penghargaan berupa kenaikan gaji, bonus maupun promosi bagi pegawai berkinerja tinggi, memberikan penghargaan yang lebih kecil bagi pegawai berkinerja rata-rata dan juga dimungkinkan untuk memecat pegawai dengan kinerja paling rendah.

Selain itu, berdasarkan expectancy theory, dijelaskan bahwa motivasi merupakan fungsi dari persepsi dan ekspektasi individu atas lingkungannya yang mereka bentuk berdasarkan persepsi tersebut. Dengan demikian, hasil penelitian ini membuktikan pemberian reward dengan implementasi FDRPA akan dapat membentuk ekspektasi karyawan bahwa penghargaan yang akan diterima memotivasi karyawan untuk menjadi top performers.

\section{Hubungan FDRPA dan Retensi}

Hasil penelitian ini membuktikan bahwa terdapat pengaruh positif antara FDRPA terhadap retensi; artinya, penerapan FDRPA mempengaruhi tingkat retensi karyawan. Hal ini juga mengkonfirmasi hasil-hasil penelitian sebelumnya bahwa FDRPA dapat memiliki "sorting effect" melalui proses daya tarik dan retensi pegawai (Ghosh et al., 2013; Hausknecht et al., 2008; Rynes et al., 2005).

Hasil dari penelitian ini karenanya mengidentifikasi bahwa organisasi yang menerapkan FDRPA dinilai memiliki daya tarik tersendiri bagi karyawan dengan potensi kinerja tinggi. Karyawan cenderung lebih tertarik pada organisasi yang memberikan penghargaan kepada pegawainya berdasarkan kriteria professionalisme kerja (Hamukwaya \& Yazdanifard, 2014). 
Hubungan Motivasi Memediasi FDRPA terhadap Task Performance

Hasil analisis dalam penelitian ini menunjukan motivasi terbukti memediasi hubungan penerapan FDRPA terhadap task performance secara positif dan signifikan. Artinya, motivasi dalam hal ini memiliki peran dalam mempengaruhi task performance karyawan. Sementara itu, FDRPA dikenal sebagai suatu metode atau sistem penilaian kinerja yang bersifat obyektif dalam menilai kinerja setiap individu (Loberg et al., 2021). Tetapi, FDRPA juga mampu menghindarkan unit bisnis dari beberapa bias dan error yang sering terjadi jika menerapkan sistem penilaian kinerja berbasis absolute rating (Hartmann \& Schreck, 2018; Malhotra \& Mukherjee, 2013).

Hal ini sejalan dengan apa yang disebut sebagai incentive effect, dimana melalui penerapan FDRPA para manajer dapat memberikan penghargaan yang besar kepada pegawai berkinerja tinggi, memberikan penghargaan yang lebih kecil bagi pegawai berkinerja rata-rata dan juga dimungkinkan memberikan sanksi pada pegawai berkinerja paling rendah (Bawa, 2019; Rynes et al., 2005; Thomason et al., 2018). Melalui penilaian yang bersifat obyektif tersebut, unit bisnis mampu mengidentifikasi dengan jelas mana kelompok Relationship Manager yang tergolong berkinerja tinggi, berkinerja ratarata serta berkinerja rendah, sehingga perusahaan bisa menentukan setiap keputusan yang diambil atas hasil penilaian tersebut seperti keputusan mengusulkan promosi dan bonus kinerja bagi relationship manager yang berkinerja tinggi.

\section{Hubungan Retensi Memediasi FDRPA} terhadap Task Performance

Hasil penelitian ini menunjukkan retensi karyawan terbukti memediasi hubungan antara implementasi FDRPA terhadap task performance. Sejmlah peneliti menyatakan bahwa pegawai yang berpotensi tinggi cenderung akan tertarik pada perusahaan yang menerapkan FDRPA (Moon et al., 2015; Thomason et al., 2018). Karyawan cenderung lebih tertarik pada perusahaan yang memberikan penghargaan kepada pegawainya berdasarkan job performance. Bagi calon pegawai yang berpotensi tinggi, perusahaan dengan penerapan FDRPA dapat dipandang sebagai tempat yang menarik untuk berkarir dikarenakan potensi dan kemampuan mereka akan diapresiasi dan bisa terus dikembangkan (Blume et al., 2013; Yu, 2014).

Selain itu, beberapa kriteria FDRPA merupakan faktor dari retensi, seperti peluang agar dapat dipromosikan dan berkembang (Cook, 2012; Mulligan \& Schaefer, 2011), dan penghargaan ekstrinsik (Ghosh et al., 2013; Giumetti et al., 2015; Hausknecht et $a l ., 2008)$. Melalui hasil yang diperoleh dalam penelitian ini, diketahui bahwa retensi memiliki peran mediasi antara FDRPA dan task performance. Hal ini membuktikan teori sebelumnya bahwa retensi memiliki peranan penting terhadap hubungan antara FDRPA dan task performance. FDRPA karenanya dinilai mampu mendesak pihak relationship manager yang ada saat ini untuk terus mengembangkan potensi dan kinerjanya, sehingga dapat tetap memiliki daya saing dengan pihak relationship manager yang baru bergabung. hal ini karenanya juga mendorong relationship manager yang telah ada saat ini dalam perusahaan untuk terus meningkatkan task performance mereka.

\section{SIMPULAN}

Berdasarkan penelitian yang telah dilakukan tentang hubungan antara FDRPA terhadap task performance dengan mediasi oleh motivasi atau retensi, maka dapat disimpulkan beberapa hal yaitu terdapat hubungan yang positif dan signifikan antara 
FDRPA dengan motivasi, FDRPA dengan retensi, FDRPA dengan task performance, motivasi dengan task performance, dan retensi dengan task performance. Selanjutnya, motivasi dan retensi juga terbukti memediasi secara positif signifikan hubungan antara FDRPA terhadap task performance.

Beberapa implikasi manajerial yang dimunculkan berdasarkan hasil penelitian. Pertama, perusahaan dapat tetap mempertahankan FDRPA sebagai sistem penilaian kinerjanya, dimana berdasarkan analisis yang telah dilakukan FDRPA terbukti dapat meningkatkan task performance dari pihak relationship manager. Namun demikian, pemangku kepentingan juga perlu memastikan dalam beberapa tahun ke depan dampak positif terhadap task performance ini tetap dapat dipertahankan. Meskipun beberapa penelitian terdahulu menunjukkan bahwa pengaruh positif terhadap task performance ini muncul pada tahap-tahap awal penerapan FDRPA, telah dijelaskan sebelumnya bahwa setiap perusahaan dapat menerapkan strategi FDRPA yang berbeda karena kondisi kerja yang juga berbeda. Perusahaan dapat mem pertimbangkan bagaimana desain FDRPA yang tepat untuk diterapkan pada periodeperiode berikutnya.

Terdapat beberapa keterbasan penelitian yang kemudian dapat dikembangkan dalam penelitian selanjutnya. Pertama, jumlah sampel yang digunakan tidak terlalu besar. Meskipun, penentuan jumlah sampel sudah sesuai dengan metodologi, namun hal ini juga terbatas oleh jumlah populasi pada subjek penelitian. Kedua, penelitian ini menggunakan single level method; dimana retensi merupakan variabel yang melekat pada tingkat organisasi, sementara FDRPA, motivasi, dan task performance di sisi lain merupakan variabel yang melekat pada level individu. Adanya perbedaan level variabel pada penelitian ini lebih tepat bila dianalisis menggunakan metode multi-level bottom up. Ketiga, hasil dari penelitian menawarkan bukti empiris pada satu subjek penelitian dimana penelitian ini hanya dilakukan di unit bisnis perbankan yang pendanaan dan operasionalnya dibawah kendali pemerintah langsung. Sehingga hasil dari penelitian ini tidak dapat dijadikan acuan secara umum mengenai penerapan FDRPA pada perusahaan lainnya, dimana setiap perusahaan tentu memiliki budaya kerja yang berbeda yang dipengaruhi oleh banyak faktor.

\section{REFERENSI}

Aguinis, H. (2007). Performance management. Prentice-Hall.

Aguinis, H. (2013). Performance management $\left(3^{\text {rd }}\right.$ ed.). Pearson New International Edition.

Al-Jedaia, Y., \& Mehrez, A. (2020). The effect of performance appraisal on job performance in governmental sector: The mediating role of motivation. Management Science Letters, 10(9), 2077-2088. doi: 10.5267/j.msl.2020. 2.003 .

Al Kurdi, B., Alshurideh, M., \& Al Afaishat, T. (2020). Employee retention and organizational performance: Evidence from banking industry. Management Science Letters, 10(16), 3981-3990. doi: 10.5267/j.msl.2020.7.011.

Bates, S. (2003). Forced ranking. https://www.shrm.org/hr-today/news/ hr-magazine/pages/0603bates.aspx.

Bawa, M. A. (2019). Employee motivation and productivity: A review of literature and implications for management practice. International Jouranal of Economics, Commerce and, Management., 5(12), 662-673. Retrieved from https://www.researchgate.net/publicatio n/334263937_EMPLOYEE_MOTIVA TION_AND_PRODUCTIVITY_A_RE VIEW_OF_LITERATURE_AND_IMP LICATIONS_FOR_MANAGEMENT_ PRACTICE. 
Berger, J., Harbring, C., \& Sliwka, D. (2013). Performance appraisals and the impact of forced distribution - An experimental investigation. Management Science, 59(1), 54-68. Retrieved from http://www.jstor.org/stable/23359605.

Blume, B. D., Baldwin, T. T., \& Rubin, R. S. (2009). Reactions to different types of forced distribution performance evaluation systems. Journal of Business and Psychology, 24(1), 77-91. doi: 10.1007/s10869-009-9093-5.

Blume, B. D., Rubin, R. S., \& Baldwin, T. T. (2013). Who is attracted to an organisation using a forced distribution performance management system? Human Resource Management Journal, 23(4), 360-378. doi: 10.1111/17488583.12016 .

Burnham, T. (2015). Public goods with punishment \& payment for relative rank. SSRN Electronic Journal. doi: 10.2139/ssrn.2623763.

Cable, D. M., \& Judge, T. A. (1994). Pay preferences and job search decisions: A Person-organization fit perspective. Personnel Psychology, 47(2), 317-348. doi: $\quad 10.1111 / j .1744-6570.1994 . t b 017$ 27.x.

Chattopadhayay, R., \& Ghosh, A. K. (2012). Performance appraisal based on a forced distribution system: Its drawbacks and remedies. International Journal of Productivity and Performance Management, 61(8), 881896. doi: 10.1108/17410401211277138.

Chattopadhyay, R. (2019). Impact of forced distribution system of performance evaluation on organizational citizenship behaviour. Global Business Review, 20(3), 826-837. doi: 10.1177/09721509 17721819.

Cook, N. (2012). Effects of forced distribution method of performance evaluation on employee motivation in a manufacturing environment. Walden University.

Fudge, R. S., \& Schlacter, J. L. (1999). Motivating employees to act ethically:
An expectancy theory approach. Journal of Business Ethics, 18(3), 295304. doi: 10.1023/A:1005801022353.

Gerhart, B., \& Fang, M. (2015). Pay, intrinsic motivation, extrinsic motivation, performance, and creativity in the workplace: Revisiting long-held beliefs. Annual Review of Organizational Psychology and Organizational Behavior, 2(April), 489-521. doi: 10.1146/annurev-orgpsych-032414111418.

Ghosh, P., Satyawadi, R., Joshi, J. P., \& Shadman, M. (2013). Who stays with you? Factors predicting employees' intention to stay. International Journal of Organizational Analysis, 21(3), 288312. doi: 10.1108/IJOA-Sep-2011-0511

Ghozali, I. (2009). Analisis multivariate lanjutan dengan program SPSS. Badan Penerbit Universitas Diponegoro.

Giumetti, G. W., Schroeder, A. N., \& Switzer, F. S. (2015). Forced distribution rating systems: When does "rank and yank" lead to adverse impact? Journal of Applied Psychology, 100(1), 180-193. doi: 10.1037/a0037191.

Grote, D. (2006). Forced ranking: Making performance management work. In Working Knowledge for Business Leader (pp. 11-14). Harvard Business School Press.

Hair, J. F., Black, W., Babin, B., \& Anderson, R. (2014). Multivariate data analysis ( $7^{\text {th }}$ eds.). Pearson Education Limited.

Hamukwaya, S. I., \& Yazdanifard, R. (2014). How a proper performance related reward system can contribute to work performance excellence. Open Journal of Business and Management, 2(3), 189-194. doi: 10.4236/ojbm.2014. 23023.

Hartmann, F., \& Schreck, P. (2018). Rankings, performance, and sabotage: The moderating effects of target setting. European Accounting Review, 27(2), 363-382. doi: 10.1080/09638180.2016. 1244015 .

Hausknecht, J., Rodda, J. M., \& Howard, M. 
J. (2008). Targeted employee retention: performance-based and job-related differences in reported reasons for staying. Human Resource Management, 48(2), 269-288. doi: 10.1002/hrm. 20279.

Jayasuriya, Y., \& Dasanayaka, S. W. (2016). Impact of bell curve forced ranking performance appraisal on employees motivation. Proceedings, 37-41. International Conference in Technology Management (INCOTeM 2016).

Kanwal, K., \& Syed, M. (2017). Impact of reward system on employee performance in banking sector. RADS Journal of Social Sciencess \& Business Management, 4(2), 82-103. Retrieved from http://jssbm.juw.edu.pk/index. php/jssbm/article/view/44.

Kwon, K., Bae, J., \& Lawler, J. J. (2012). High commitment HR practices and top performers: Impacts on organizational commitment. Management International Review, 50(1), 57-80. doi: 10.1007/s11575-009-0023-6.

Lawler, E. E. I. (1973). Motivation in work organization. Brooks/Cole Publishing Co. Retrieved from https://eric.ed.gov/ ?id=ED091542.

Loberg, L., Nüesch, S., \& Foege, J. N. (2021). Forced distribution rating systems and team collaboration. Journal of Economic Behavior and Organization, 188, 18-35. doi: 10.1016/j.jebo.2021. 04.035.

M. Badubi, R. (2017). Theories of motivation and their application in organizations: A risk analysis. International Journal of Innovation and Economic Development, 3(3), 44-51. doi: 10.18775/ijied.1849-7551-7020.2015. 33.2004.

Malhotra, G., \& Mukherjee, A. (2013). Comparative study of forced distribution and absolute rating performance management systems. International Journal of Business Excellence, 6(2), 121-130. doi: 10.1504/IJBEX.2013.052475.
Moon, S. H., Scullen, S. E., \& Latham, G. P. (2015). Precarious curve ahead: The effects of forced distribution rating systems on job performance. Human Resource Management Review, 26(2), 166-179. doi: 10.1016/j.hrmr.2015.12. 002.

Motowidlo, S. J., \& Van Scotter, J. R. (1994). Evidence that task performance should be distinguished from contextual performance. Journal of Applied Psychology, 79(4), 475-480. doi: 10.1037/0021-9010.79.4.475.

Mulligan, J. R., \& Schaefer, R. A. B. (2011). A new hope for rank and yank. Journal of Leadership and Organizational Studies, 18(3), 385-396. doi: $10.1177 / 1548051811405206$.

Naim, M. F., \& Lenka, U. (2018). Development and retention of Generation Y employees: A conceptual framework. Employee Relations, 40(2), 433-455. doi: 10.1108/ER-09-20160172.

Osborne, T., \& McCann, L. (2004). FDRS and age-related employment discrimination. Human Rights Magazine, 31, 6-9. Retrieved from https://heinonline. org/HOL/LandingPage?handle=hein.jo urnals/huri31\&div=20\&id=\&page $=$.

Parijat, P., \& Bagga, S. (2014). Victor Vroom's expectancy theory of motivation - An evaluation. International Journal of Business and Management, 7(9), 1-8. Retrived from http://irjbm.org/irjbm2013/Sep2014/Pa per1.pdf.

Pearce, J. L., \& Porter, L. W. (1986). Employee responses to formal performance appraisal feedback. Journal of Applied Psychology, 71(2), 211-218. doi: 10.1037/0021-9010. 71.2.211.

Pradhan, R. K., \& Jena, L. K. (2017). Employee performance at workplace: Conceptual model and empirical validation. Business Perspectives and Research, 5(1), 69-85. doi: 10.1177/ 2278533716671630. 
Reizer, A., Brender-Ilan, Y., \& Sheaffer, Z. (2019). Employee motivation, emotions, and performance: a longitudinal diary study. Journal of Managerial Psychology, 34(6), 415428. doi: 10.1108/JMP-07-2018-0299.

Rynes, S. L., Gerhart, B., \& Parks, L. (2005). Personnel psychology: Performance evaluation and pav for performance. Annual Review of Psychology, 56, 571600. doi: 10.1146/annurev.psych.56. 091103.070254.

Sari, J., \& Suhariadi, F. (2019). Kontrak psikologis terhadap commitment to change: Resiliensi akademik sebagai variabel mediasi. Persona: Jurnal Psikologi Indonesia, 8(2), 178-192. doi: 10.30996/persona.v8i2.2535.

Scullen, S. E., Bergey, P. K., \& Aiman-Smith, L. (2005). Forced distribution rating systems and the improvement of workforce potential: A baseline simulation. Personnel Psychology, 58(1), 1-32. doi: 10.1111/j.1744-6570. 2005.00361.x.

Seng, N. L., \& Arumugam, T. (2017). Financial reward and motivation toward employee job performance in the hospitality industry in Klang Valley. Electronic Journal of Business \& Management, 2(1), 51-60. Retrieved from https://ejbm.sites.apiit.edu.my/ files/2018/05/Paper5_Financial_Rewar d_And_Motivation_Toward_Employee _Job_Performance_In_The_Hospitality _Industry_In_Klang_Valley.pdf.

Stewart, S. M., Gruys, M. L., \& Storm, M. (2010). Forced distribution performance evaluation systems: Advantages, disadvantages and keys to implementation. Journal of Management and Organization, 16(1), 168-179. doi: 10.5172/jmo.16.1.168.

Syahreza, D. S., Lumbanraja, P., Dalimunthe, R. F., \& Absah, Y. (2017). Compensation, employee performance, and mediating role of retention: A study of differential semantic scales. European Research Studies Journal, 20(4), 151-159. doi: 10.35808/ersj/825.
Thomason, S. J., Brownlee, A., \& Harris, A. B. (2018). Forced distribution systems and attracting top talent. International Journal of Productivity and Performance Management, 67(7), 169176. doi: 10.1080/03081069108717452.

Turban, D. B., \& Keon, T. L. (1993). Organizational attractiveness: An interactionist perspective. Journal of Applied Psychology, 78(2), 184-193. doi: 10.1037/0021-9010.78.2.184.

Wassem, M., Baig, S. A., Abrar, M., Hashim, M., Zia-Ur-Rehman, M., Awan, U., Amjad, F., \& Nawab, Y. (2019). Impact of capacity building and managerial support on employees' performance: The moderating role of employees' retention. Sage Open, 9(3). doi: 10.1177/2158244019859957.

Wigfield, A., \& Eccles, J. S. (2000). Expectancy-value theory of achievement motivation. Contemporary Educational Psychology, 25(1), 68-81. doi: 10.1006/ceps.1999.1015.

Yu, K. Y. (2014). Person-organization fit effects on organizational attraction: A test of an expectations-based model. Organizational Behavior and Human Decision Processes, 124(1), 75-94. doi: 10.1016/j.obhdp.2013.12.005.

Zenger, T. R. (1992). Why do employers only reward extreme performance? Examining the relationships among performance, pay, and turnover. Administrative Science Quarterly, 37(2), 198-219. doi: 10.2307/2393221.

Zheng, W., Zhang, M., \& Li, H. (2012). Performance appraisal process and organizational citizenship behavior. Journal of Managerial Psychology, 27(7), 732-752. doi: 10.1108/02683941 211259548 . 
Jurnal Samudra Ekonomi dan Bisnis

P-ISSN 2089-1989

Volume 13, Nomor 1, Januari 2022

E-ISSN 2614-1523

Terakreditasi (SK No. 28/E/KPT/2019) 